Research Journal of Applied Sciences 7 (3): 199-207, 2012

ISSN: $1815-932 \mathrm{X}$

(C) Medwell Journals, 2012

\title{
Adaptability of Traditional Arab House to its Environment in Core Tripoli, Libya
}

\author{
S.M. Sharif, M.F.M. Zain and M. Surat \\ Department of Architecture, Universiti Kebangsaan Malaysia, 43600 Bangi, Malaysia
}

\begin{abstract}
Indigenous house form is a kind of vernacular architecture typical of valuable heritage sites like core Tripoli in Libya. These habitats are blessed with considerable traditional housing stock. A case study research approach qualitatively evaluates adaptation factors associated with traditional Arab family residences as at the year 2010 in Core Tripoli neighborhoods. Exclusively, physical and social housing typology characters were measured. Qualitatively, housing environments generate user adaptation from a combination competing social and physical requirements like thermal comfort. A double single storey Arab housing type, shared by multiple families seems to dominate Tripoli landscape. Here, spatial hierarchical order separates public from private zones with strong sense of neighborly interaction and social cohesiveness internally. The research findings suggest the congruence of social value of privacy and physical factor of natural ventilation. From these findings, it is evident that social and physical environmental determinants coincide hence, enhancing the sustainability housing total adaptability.
\end{abstract}

Key words: Privacy, courtyard housing, thermal comfort, vernacular housing, coincide, Malaysia

\section{INTRODUCTION}

Vernacular housing designates the common, nonscientific pattern of residence. It is an indigenous building style using local materials and traditional methods of construction and ornament especially as distinguished from academic or historical architectural styles. Architectural designs reflect the natural environment. Flat roofs or no roofs at all are sensible choices in regions with low rainfall. People who live in rainy areas though, logically conclude that steeply pitched roofs are a better choice. Those who inhabit flood prone tropical rainy areas like Malaysia and Thailand where temperatures are hot often construct thick or cavity-walled houses on stilts. This provides flood protection and allows free circulation of cool breezes beneath the house and through cracks in the walls. Literally, thousands of different types of vernacular houses punctuate the landscapes of folk culture regions around the world. However, traditional Arab housing form assumes compact settlement outlook within which courtyard system fitted with spatial hierarchy, in response to thermal needs of ventilation physically. Socially, the extended family dwellers are guaranteed mutual privacy.

Problem statement: Generally, the traditional Arab housing typology has some features of specific adaptability features to its peculiar environment. Tripoli, Libya is an old traditional Arab settlement with longestablished houses that have stood the test of time. A research effort is therefore necessary to contribute to the understanding these distinctive adaptable residential typologies. The research employed qualitative case study approach to examine the basic styles used by traditional builders/architects. The built environment interventions met to a great extend the user social and physical demands. The key research concerns geared at enquiring the characteristics of traditional Arab house generally and Tripoli specifically. Others are the traditional Arab house physical and social adaptability features to the environment. It also enquires how modern architecture distorts the adaptability of the traditional Arab house in the case study. Tripoli core houses of Al Madina AlQadimah (old city) are sampled for their physical and social environmental values.

Islamic values shape houses and settlements patterns of many core Islamic societies of the Middle East and Africa. Here, the application of local building materials, intermediate technology seems to adapt vernacular residences to their natural environment. Similarly, psychological values of Islamic principles influence residents' social intercourse hence, spatial hierarchy of spaces afford climatic response and spatial utility for a variety of domestic functions.

The research hypothesis includes establishing relationship between social and physical traditional Arab house environments in Tripoli recognizing differences between social and physical traditional Arab house adaptation in Tripoli; ascertaining whether there is difference between traditional Arab houses in core Tripoli,

Corresponding Author: S.M. Sharif, Department of Architecture, Universiti Kebangsaan Malaysia, 43600 Bangi, Malaysia 
social features of core Tripoli residence and adaptation difference between social and physical characters of traditional Arab houses.

\section{STUDY AREA: TRIPOLI CORE CITY}

In order to carry out the investigation it was necessary to locate an area of investigation; experiencing development and yet still have enough traditional houses left to provide needed information. To study the social and environmental adaptability of the traditional Libyan Arab houses, there had to be a variety of patterns of spatial configurations from different house styles. In order to obtain several house types as representative samples, the selected area had to be physically under development and get an adequate number of houses with different construction dates (Fig. 1).

Selected settlements for sampling are Bab Al-Bahr, Houmt Gheryan, Al-Hara and Al Baladiya. A total of 8 residential units are observed for privacy (seclusion of women) and thermal comfort. These sites were chosen because quantity and variety of traditional houses met the requirements of the research which was established prior to collecting data.

\section{Privacy evaluation:}

- Inaccessibility of male visitors or passers by to the interior of the house (women's domain)

- Adequacy of indoor and outdoor spaces for the women's private use

- Hierarchy of spaces

- Opacity (lot coverage)

- Circulation complexity

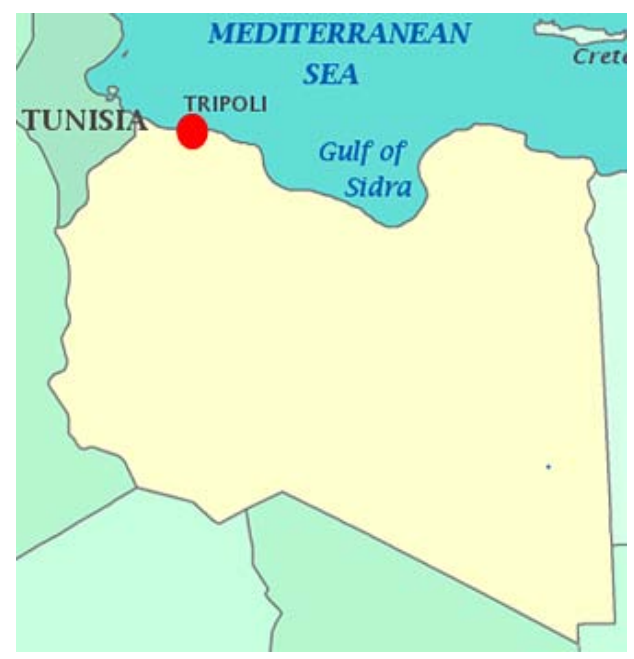

Fig. 1: Map showing the location in Libya

\section{Thermal comfort evaluation:}

- Cross ventilation (openings and their locations, size of courtyard and orientation)

- Temperature, humidity and air velocity

- Aspect ratio

- Availability of shade

- Size of courtyard

- Building geometry

Thermal comfort is a professional expression of satisfaction within his state of mind that needs to be maintained for health of occupants of buildings and other enclosed environments (ANSI/ASHRAE Standard). The attainment of such a standard deserves the attention of architects and engineers to balance heating, ventilation and air conditioning (naturally or mechanically) in ensuring energy efficiency. Natural ventilation as offered by TAH System has the potential to reduce the energy required for cooling and ventilating residential buildings while still providing acceptable thermal comfort and indoor air quality. It could be observed that traditional Arab housing typology is energy efficient due natural ventilation and lighting. Figure 2 shows air movement as observed within interior spaces of typical $\mathrm{TAH}$.

Local traditional Arab house form of core tripoli: The Arab world lies within the hot arid climatic zones hence,

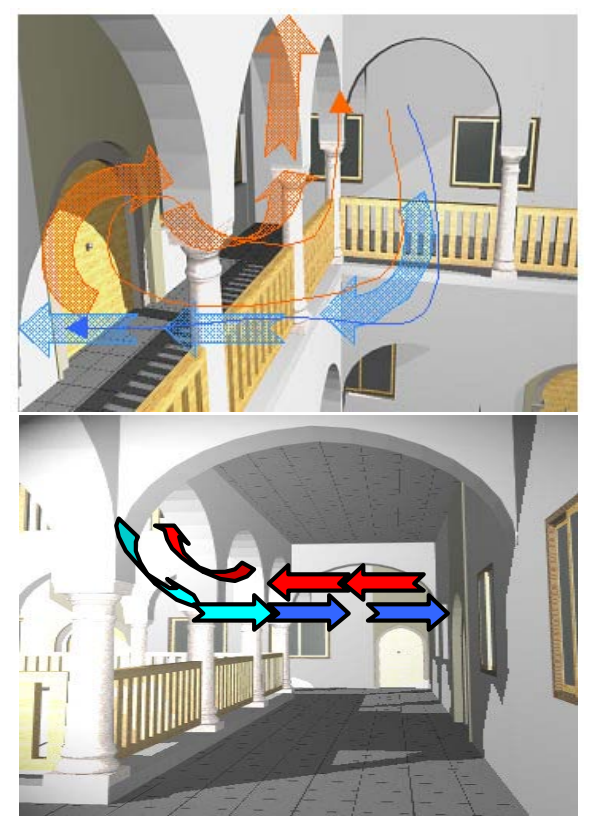

Fig. 2: The corridor area maintains varying air pressure (high and low). The gallery is associated with cooling air currents within the space 


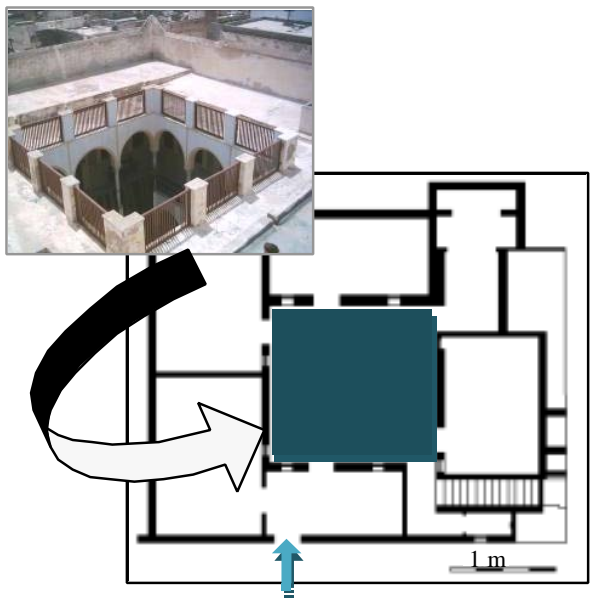

Fig. 3: The location of the courtyard. Researcher's fieldwork in 2010

its building techniques of the developed over centuries of construction, to promote passive climatic conditioning to protect inhabitants from inclement environment. Despite, local variations in solutions to environmental problems, traditional Arab ideas and techniques of city planning, building form and constructions technology offer great insight to contemporary architecture and planning of Middle East.

The traditional Arab courtyard house is possibly one of the most enduring and wide spread housing types in history. It is found in antiquity and modern times, in most world regions in different climates and cultures. Local building materials are of thermal properties that fit appropriately into the desert climate. The construction system depends on load bearing thick walls with minimum outside openings. This system enhances the wall resistance to heat transference and modifies the indoor microclimate within comfort zone (Fig. 3).

The courtyard concept makes it the most common domestic type in Islamic culture. The emphasis is on security and privacy thereby protecting the sanctity of the family unit. Its unique congruence with features and tenets of Islam is possibly the central reason for its attainment of advanced level of development and refinement in the Arab-Muslim world. The inner space of the house is essentially screened off from hot or cold winds and thus becomes a climatic tabula rasa to be modulated according to human and cultural needs and demands of the exterior climate of the locale. The traditional Arab courtyard house is obviously meets the social and environmental needs of its inhabitants. Physically, it integrates gardens, courts and buildings into a coherent whole. Socially, its architectural style adapts
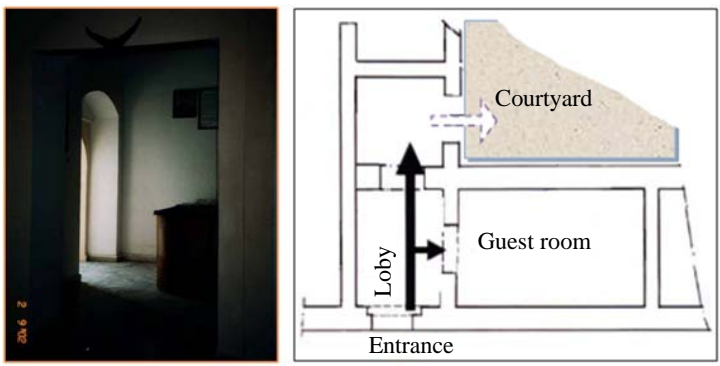

Fig. 4: The indirect customary entrance aimed at deflecting visual access. Researcher's fieldwork

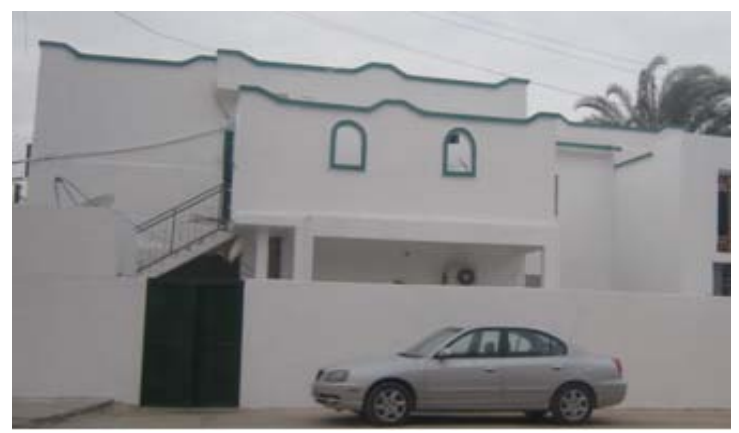

Fig. 5: A typical Arab house facade (min. external openings) illustrates symbolism and expressionism. Researcher's fieldwork in 2010

user spatial ordering that promotes spiritual gender segregation, a vital Islamic tenet. Much of the reality of space and enclosure as well as the symbolism and decorations in the traditional Arab house is not the direct expression of a philosophy or epistemology underlying a design ambition. It is the actualization of forces of nature, transformed through the process of symbolism into architecture that celebrates human values whilst acknowledging eternal ones. Figure 4 shows hierarchy of spaces and visual access principles of Islamic housing system. Figure 5 shows the need for minimum external openings in such houses.

\section{REVIEW OF HOUSING ADAPTABILITY THEORIES}

This review of residential adaptation identifies basic problems typical of such studies methodologies applied; research outcomes and the relevance of those to this thesis. Apparent approaches include user perception of satisfaction or PREQ; RESS-A Methodological tool; P-E or Person Environment Congruence, housing modification-HoMi and QoL-Quality of Life Assessment. 
Quality of Life (QoL) assessment of formal housing: QoL studies by Marans (2003) directly or indirectly test Maslow's Theory of basic needs but Sulaiman and Yahaya (1987) examined satisfaction in terms of:

- Housing deficit-objective measurement

- Overall satisfaction with housing and its environment

- Stage in family life-cycle = Demographic characteristic

Perception of satisfaction (PREQ): PREQ involves testing of a path model of residential adaptation. This is measured as the user perception of his or her residential environment, specifically neighborhood attachment. It employs quantitative research approach covering four areas:

- Architecture and planning features

- Social relations features

- Punctual and in-network services

- Context features

The research outcome shows that Perceived Residential Environmental Quality (PREQ) is suggested directly related to neighborhood attachment:

- Arch and planning features

- Social relations features

- Punctual and in-network services

- Context features

Residential Environmental Satisfaction Scale (RESS): RESS introduces an integrative and more comprehensive approach to the measurement of residential environmental adaptation. It involves quantitative data collection and multivariate analysis. The relevance of RESS in this research is in the satisfaction of the Theoretical ThreeComponent Model of Neighborhood, house and neighbors. Moreover, the priority of the social climate in vulnerable groups is worthy of testing (Adriaanse, 2007).

Housing modification phenomenology: Generally, users modify their residences to adapt to changing needs. And the phenomenology refers to logical investigation involving careful connection to the philosophy existentiality. The phenomenon of effecting changes to housing by users could be associated with changing needs due social, physical and economic dimensions. These may emanate from (Marans, 2003):

- Project management, specifically design and construction
- Occupant socio-cultural characteristics

- Housing conditions and ranking

- Residential satisfaction due to adaptation

Philosophy of phenomenological adaptation: Sartre and Merleau-Ponty saw phenomenology as a means of broadening the narrow empiricist, psychological assumptions about human existence, widening the scope of philosophy to capture life as it is lived. Thus, Sartre's encounter with phenomenology through Raymond Aron allowed one to philosophize about a wine glass (Marans, 2003).

Effects of culture on man's shelter: Culture is widely used to analyze the house form by architects, planners, cultural geographers and anthropologists alike. The idea of choice that people make between available house forms is in response to their cultural needs as suggested by Rapoport. This idea is least tenable as far as it appears to imply that people choose, in the construction of their houses from a range of available house forms or catalogue, the ones that most suit them (or their cultural requirements).

Experts like Paul Oliver identified the fundamental difficulty involved in explaining vernacular house forms. It is therefore arguable that designers' misconceptions of vernacular forms.

Culture and environment relationship: Psychological processes link culture and physical environment through mental internal activities and behavioral external features (Altman and Chemers, 1980). Hence, suggested a theoretical socio-psychological perspective of the relationship between the pair global partners. The core features of the theory are:

- The physical environment links user interpersonal relations and social interaction

- Manifested in perceptions, cognitions and attitudes

- Culture links to the environment psychologically and socially

- Imaginary psycho-social dimension of environment ties to the physical setting

The researchers opined that the 21 st century modern housing system's reductionism of Islamic housing spatial dictates needs to be reversed. This is to accommodate user socio-cultural ideals. Consequently, the residential Arab typology has to be abstracted for its core physical and social values which leads to psychological 
satisfaction of residents. These include physical dimensions of thermal comfort and respect to spatial identity that guarantees family privacy.

\section{RESEARCH METHODOLOGY}

The variety of data collected was analysed using cross analysis and triangulation for convergence of both quantitative and qualitative data. A qualitative evaluation strategy was employed to describe the housing adaptation features of the case study, identify its trend and establish the physical and social variables of housing alteration. In response to Strauss and Corbin's recommendation, initially at least, the interview materials were analyzed line by line. Subsequently, these data deductions were coded under a number of different conceptual headings such as typological, physical and social dimensions hence, generating the open codes.

Qualitative research paradigm supported by quantitative evidence informed data collection and analysis. A case study research design analyzes the TAH typology of the extended family compounds (group of residences sharing common facilities) through the development of a grounded theory. Triangulation of quantitative and qualitative data led to data convergence. Based on De Vaus (2002), 204 samples (at 93\% confidence level) were selected (Table 1 and 2).

Data for this study was limited to the attitudes, opinions and perceptions as reported by survey respondents in the four out of the six neighborhoods. These are Bab-Albahar (BA), Homat Geryan (HG), Al-Hara $(\mathrm{AH})$ and $\mathrm{Al}$ Baladiya'a $(\mathrm{AB})$. The study relies on both

Table 1: Simple random sampling size at $90-99 \%$ confidence level

\begin{tabular}{lccc}
\hline Sampling error & Sample size & Sampling error & Sample size \\
\hline 1.0 & 10,000 & 6.0 & 277 \\
1.5 & 4,500 & 6.5 & 237 \\
2.0 & 2,500 & 7.0 & 204 \\
2.5 & 1,600 & 7.5 & 178 \\
3.0 & 1,100 & 8.0 & 156 \\
3.5 & 816 & 8.5 & 138 \\
4.0 & 625 & 9.0 & 123 \\
4.5 & 494 & 9.5 & 110 \\
5.0 & 400 & 10.0 & 100 \\
5.5 & 330 & - & - \\
\hline De Vaus (2002) & & &
\end{tabular}

Table 2: Sample size based on population estimates of the settlements/wards

Estimated Quantitative In-depth

\begin{tabular}{lccc} 
Settlements & $\begin{array}{c}\text { Estimated } \\
\text { population }\end{array}$ & $\begin{array}{c}\text { Quantitative } \\
\text { sample size }\end{array}$ & $\begin{array}{c}\text { In-depth } \\
\text { interview }\end{array}$ \\
\hline Bab-Albahar (BA) & 38,980 & 71 & 3 \\
Homat Geryan (HG) & 28,000 & 51 & 3 \\
Al-Hara (AH) & 28,000 & 51 & 3 \\
Al Baladiya a (AB) & 17,019 & 31 & 3 \\
Total & 112,000 & 204 & 12 \\
\hline
\end{tabular}

Based on cluster sampling tied to neighborhood population Tripoli municipality retrospective and prospective accounts of housing adaptation in the form of alteration, home improvement and addition. Data sources are as follows:

- Key informant interview 3 each of architects, planners, craftsmen and community leaders $(3 \times 4=12)$

- In-depth interview of 2 family of compound heads in 4 neighborhoods $(2 \times 4=8)$

- Personal observations (photographic records of compound setting +8 Layouts )

- Quantitative questionnaire (204 cluster sampling of 4 neighborhoods) and secondary data

\section{GLOBAL CONTRIBUTION OF TRADITIONAL ARAB HOUSE FORM}

Based on the research outcome, the traditional Arab house adds to existing literature on the subject. An informal scrutiny of housing within a traditionally motivated group, Arabs reveals the characters that are well suitable to the occupants environmentally as well as socially for which the core housing values are still conceptually retained. Globally, the courtyard housing is not limited to the Arab countries like Libya and Morocco but extends to other developing societies like China and Scandinavia. Generally, courtyard housing is suites residents' environmental and cultural needs.

The research shows the retention of the Vernacular Courtyard Housing System but of diminishing size. Most of the living accommodation in the research site shows adaptability to the environment as well as meeting the user cultural needs. Residential adaptation to its total environment could enrich positive aesthetics elements. These may be based primarily on a visual coherence of the settlement generated by regular street layout, vegetation, uniform single and double storey structures and the use of similar building materials as shown in Fig. 6-8.

Relevance of TAH to vernacular research: The contributions of the traditional Arab house form includes a new attitude towards vernacular housing the involvement public and private sectors in its sustainability and appropriate application of core architectural features in domestic and institutional complexes. Others are the integration of indigenous settlements into the urban landscape as a housing strategy. However, this involves public and private sector participation as well as the sensitization of architects and planners to enhance vernacular housing within urban setting. 

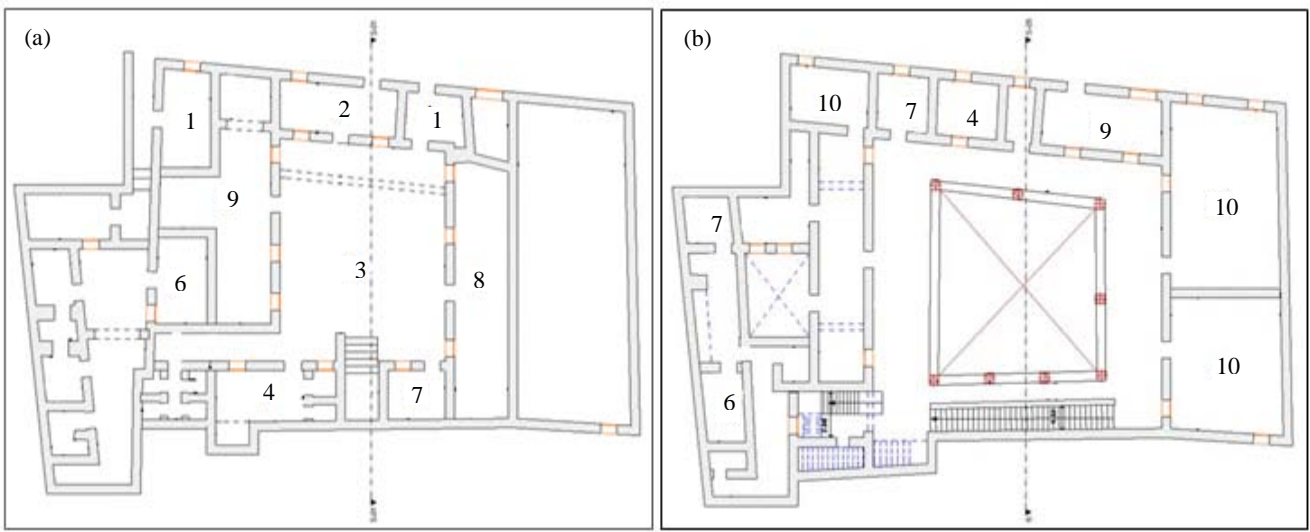

Fig. 6: a) Ground floor and b) 1st floor plans of a 2-storey Libyan Arab house, Tripoli

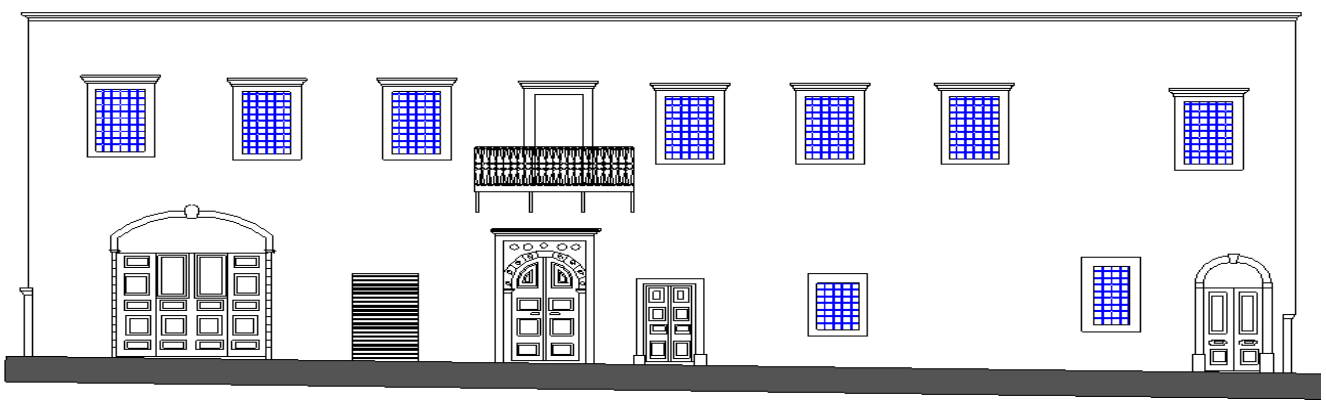

Fig. 7: Approach Facade the house above

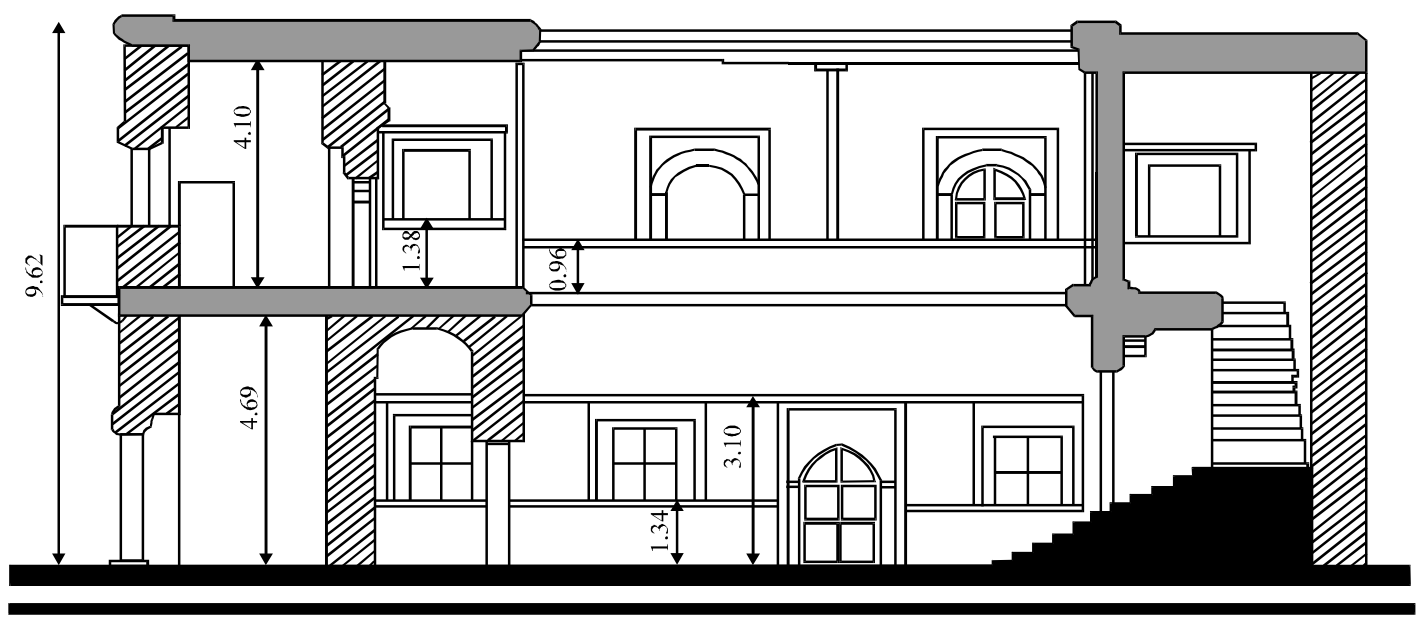

Fig. 8: Section through the house above

Revisiting vernacular housing theories: Housing theories relevant to this research are reappraised for consistency with current findings.

Abstraction of Islamic guidelines to residential design: Researches in traditional Arab house typology enables the development of residential guidelines Islamic societies generally and the Arab community specifically. Generally, the traditional houses in Tripoli may be grouped into four aspects of Islamic world view these are:

- Responsibility towards and respect for one's neighbor

- Privacy 
- Treatment of guests and visitors

- Modesty and simplicity of lifestyle, devoid of ostentatious decoration

The traditional house in Tripoli consists of the vital spaces like rooms, position of entrance and adjacency. Similarly, building elements such as boors, windows and balcony that connect inside and outside are systematically manipulated in structure and pattern.

Housing Typology Classification Theory: Type as an analytical tool is a conceptual framework for evaluating and classifying housing units. The typological analysis of residential buildings carried out by Lawrence preceded studies of the relationship between the functions ascribed to spaces and their relative position including the interface between the public and private domains. Here, samples of tenement and the shared collective spaces were evaluated for their access to access to the public domain of the street. The justification for the application of typology classification stems from the research objective. It sought to determine the adaptability of indigenous Arab house typology.

Lawrence suggested five criteria for the classification of housing types. This provides a basis of housing typology in this study. In the present study, the classification criteria of the number of rooms, layout, spatial organization and number of floors plays an important role in classifying housing types. Some of these variables are applied in housing modification. Lawrence used spatial organization of the floor plan in relation to the means of access from the public realm of the street to the private realm of each dwelling. This criterion is employed in the present study although, the public realm in this context is not well defined by streets.

Core social variables of TAH adaptability: Based on the average mean values of the four sampled neighborhoods:

- Occupancy rank 2.44 implies owner tenant and tenant only

- Level of education 2.14 secondary school level or standard 12

- No. of households living together is 3.08 means three families sharing a unit

Comparatively, all the four Tripoli Core settlements are characterized by household rentals. But they all manifest varying degree of fully rental houses. These range from minority in $\mathrm{Al}$ Baladeya $(\mathrm{AB})$ through average of the housing stock in Bab Albahar (BA); to considerable in $\mathrm{Al}$ Hara $(\mathrm{AH})$ Arab houses mostly household tenants and tenants only. An average of three families shares a residential unit. Al Baladeya (AB) has the least number of households living together.

Core physical factors of TAH adaptability: Based on the average mean values of the four sampled neighborhoods:

- Climate responsiveness 4.19 relates to location of openings or building orientation

- Physical house type 2.99 owner tenant single storey

- TAH physical features 3.80 refers to thermal protectors and privacy elements

Linking social and physical variables: The research outcome confirms the association between physical and social variables of the Arab house form as follows:

- User building experience correlates with $\mathrm{TAH}$ physical features is 0.062

- TAH Tripoli features is associated with user building experience is 0.060

- User building experience correlates with number of persons living together is 0.064

- Occupancy rank correlates with TAH identity is 0.075

- Occupancy rank correlates with climate responsiveness is 0.061

- Number of persons living together and user involvement in design is 0.072

- TAH characters correlates with length of stay in the neighborhood is 0.060

In terms of location variations, all four settlements manifest similar social and physical residential environments. This suggests commonality of social setting as well as material nature of the research sites. The whole case study lies in a compact human settlement and the sampled neighborhoods are very close to one another. Core physical determinant of Arab house design is climate responsiveness. This translates into physical house type of owner tenant single storey. Such a structure is characterized by thermal protectors and privacy elements.

In many traditional Arab settlements like Ghadames in Libya, community indoor, open, semi-open spaces and rooftops provide accessibility to individual dwelling units and define the indoor-outdoor interface. This is a modification of Lawrence's application of this criterion whereby the streets form the major domains of the public realm (Fig. 9). 


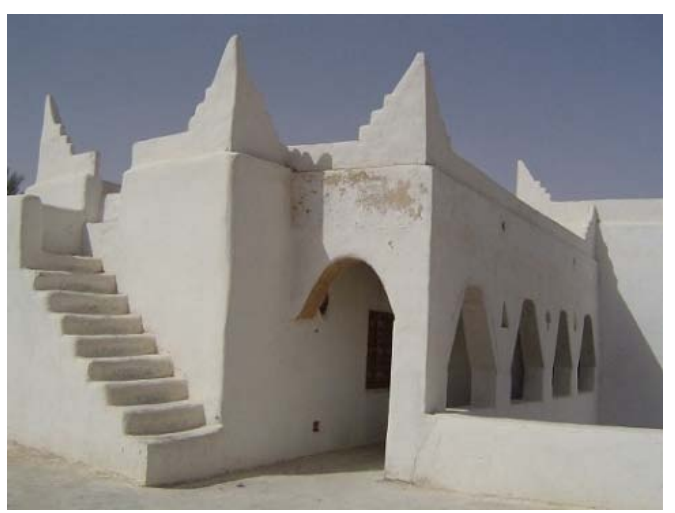

Fig. 9: A typical facade a traditional Libyan Arab house in Ghadames (Azzuz, 2000)

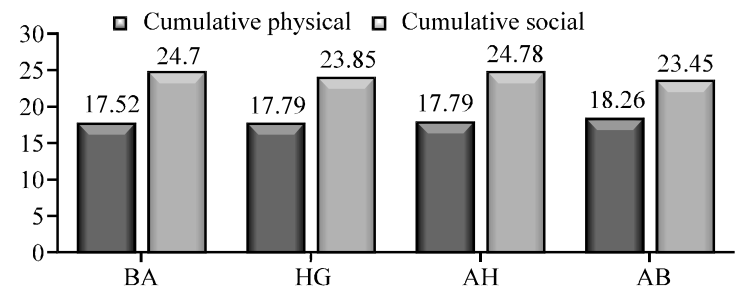

Fig. 10: Comparative cumulative neighborhood social and physical features

Comparative cumulative neighborhood social and physical features (Fig. 10) rank the research variables of the case study. The results show comparatively, Albaladeya $(\mathrm{AB})$ ranks highest physically and lowest socially. Al Hara $(\mathrm{AH})$ and Homat Geryan $(\mathrm{HG})$ are ranked second physically while Bab Albahar (BA) has the lowest cumulative physical character. But Bab Albahar (BA) has the second cumulative social character. Homat Geryan $(\mathrm{HG})$ and Albaladeya $(\mathrm{AB})$ are third and fourth, respectively in terms of cumulative neighbourhood social dimensions.

\section{CONCLUSION}

This qualitative research of a vernacular housing typology established a relationship between the Islamic concept of privacy, i.e., the isolation of women and the pertinence of the courtyard housing which responds primarily to the thermal comfort needs of the occupants and concurrently meets spatial hierarchic needs of the Arab Muslim community. First, it characterizes courtyard housing typology globally. Subsequently, it boils down to a Libyan case study. This led to the identification a variety of courtyard and non-courtyard house types, each of which manifested a degree of spatial segregation.
Thermal comfort in the case study shows the adaptability of traditional Arab house form it natural environment. Here, cross ventilation was enhanced through openings and their locations, size of courtyard and orientation. Others are temperature, humidity and air velocity; aspect ratio, availability of shade, size of courtyard and building geometry. The fundamental research issues tackled was the extent of courtyard house type's guaranteeing of household privacy socially and thermal comfort physically.

Qualitative analysis of traditional Arab housing typology in this case study led to the fitness of physical and social environments' appropriate adaptation. For one, the composition and typology of the traditional Arab housing from 1800-2010 presented in this research shows how conscious and prudent society creates its habitat within its basic means but with utmost sympathy for functional requirements and the within it low technical ability.

The adaptation of the ideal traditional complex residential unit with its four semantic variations for courtyard, desert, mountain and coastal to more functional economic courtyard model of the 21 century, honestly fit the context. Imaginative quality of these dwellings created in the transition period (independence era) was not dependent upon imported models but indigenous adjustments inspired by acculturation due enhance income. The stylistic self-sufficiency of the Libyan housing expressed through the numerous variations of convincing, locally rooted traditions within economic means.

Physical fraternity of disperse buildings into compact rectilinear dwelling was the Arabs response to climatic needs. Socially, their residential adaptation manifested in the dispersal or relocation of the elites from the traditional extended family compounds to modern layouts at the urban fringes. This coincides with their psychological desire to modernize due to culture change, especially during the revolution period.

\section{REFERENCES}

Adriaanse, C.C.M., 2007. Measuring residential satisfaction: A Residential Environmental Satisfaction Scale (RESS). J. Hous. Built Environ., 22: 287-304.

Altman, I., and M.M. Chemers, 1980. Culture and Environment. Brooks/Cole Publishing, California, USA., ISBN: 9780818503481 , pp: 1-10. 
Azzuz, I., 2000. Contemporary libyan architecture: Possibilities vs. realities. Libya, http://archnet.org/ library/documents/one-document.jsp?document $\mathrm{id}=2555$.

De Vaus, D., 2002. Surveys in Social Research. 5th Edn., Allen and Unwin, Crows Nest, Australia.
Marans, R.W., 2003. Understanding environmental quality through quality of life studies: The 2001 DAS and its use of subjective and objective indicators. Landscape Urban Plann., 65: 73-83.

Sulaiman, H. and N. Yahaya, 1987. Housing provision and satisfaction of low income households in Kuala Lumpur. Habitat Int., 11: 27-38. 